\title{
Circulating Heparan Sulfate Proteoglycan Anticoagulant from a Patient with a Plasma Cell Disorder
}

\author{
Maged S. Khoory, Michael E. Nesheim, E. J. Walter Bowie, and \\ Kenneth G. MaNx, Hematology Research Section, Mayo Clinic, \\ Rochester, Minnesota 55.901
}

\begin{abstract}
A B S T R A C T A woman, aged 68, with multiple myeloma (immunoglobulin[Ig]A kappa type) developed an anticoagulant with properties suggestive of heparin. The anticoagulant prolonged the thrombin time but not the reptilase time and was resistant to boiling, proteolytic enzyme digestion, and trichloracetic acid precipitation. The thrombin time was corrected by the addition (in vitro) of protamine sulfate or the addition of purified platelet Factor 4 ( $\mathrm{PF} 4$ ) to the plasma. The anticoagulant was isolated by PF4-Sepharose affinity chromatography and analyzed in terms of its molecular weight, uronic acid, and amino acid composition. The proteoglycan isolated had a mol wt of 116,000 and appears to consist of two 38,000 dalton polysaccharide units interconnected by peptide material totaling 39,000 daltons. Electrophoretic analysis of the pronase digested peptidoglycan using the lithium acetate-agarose technique suggested the material was of the heparan sulfate type. The peptidoglycan had about one-tenth the specific activity of commercially available heparin on a weight basis. The isolated proteoglycan was indistinguishable from commercial heparin when analyzed in terms of its ability to act as a cofactor in the antithrombin III inhibition of thrombin.
\end{abstract}

\section{INTRODUCTION}

Multiple myeloma may interfere with hemostasis in several ways (1). These include the direct complexing of the paraprotein with a coagulation factor $(2)$, or indirect interaction by interference with fibrin monomer

\footnotetext{
A preliminary report of this study was presented at a meeting of the Federation for American Societies for Experimental Biology, April 1978, Atlantic City, N. J. 1978. Fed. Proc. 37: 3. (Abstr. 618)

Dr. Khoory was supported by Blood Banking and Hemostasis training grant HL-07069 from the National Heart, Lung, and Blood Institute. Dr. Mann is an Established Investigator of the American Heart Association. Address reprint requests to Dr. Mann.

Received for publication 9 .March 1.979 and in revised form 9 November 1.979.
}

polymerization (3-5). The patient described in this study appears to be unique in that she developed a coagulopathy not directly related to the myeloma protein, but characterized by the presence of a circulating proteoglycan with properties similar to heparin in that it functioned as cofactor to antithrombin III.

The acid mucopolysaccharides are present as structual members of connective and other supporting tissues of mammals, and their presence in a variety of cell lines has been described $(6,7)$. The presence of heparin in blood has been reported (8) although this observation was byindirect procedures and has not been confirmed. The present study clearly demonstrates the presence of an antithrombin III cofactor active material in human plasma and shows that it was not associated with the plasmacytes or the immunoglobulin fraction of the plasma. The isolation and partial characterization of the material is also presented.

\section{METHODS}

Aminohexyl Sepharose was obtained from Pharmacia Fine Chemicals, Inc., Piscataway, N. J. 10\% Agarose and P-150 were obtained from Bio-Rad Laboratories, Richmond, Calif. The commercial heparin used for routine assays was from Upjohn Co., Kalamazoo, Mich. (beef lung), whereas reference standards of the acid mucopolysaccharides were provided by Dr. Martin Matthews, ${ }^{1}$ University of Chicago. Agarose for electrophoretic analysis was SeaKem (ME), obtained from Marine Colloids, Inc.; Rockland, Maine. Azorubin S dye, D-glucurono-3,6-lactone, and carbazole were from Aldrich Chemical Co., Milwaukee, Wisc. The water soluble reagent 1-ethyl-3-(3-dimethylaminopropvl)carbodiimide was from Sigma Chemical Co., St. Louis, Mo. Crude thrombin for routine anticoagulant analysis was obtained from Parke, Davis \& Co., Detroit, Mich. Pronase was obtained from Sigma Chemical Co., (protease IV). Platelet Factor 4 was purified by the method of Ruiz et al. (9). Purified bovine $\alpha$-thrombin used for examination of interaction of the inhibitor of antithrombin III was prepared by the method of Lundblad et al. (10). Bovine antithrombin III was prepared using the method of Damus and

\footnotetext{
${ }^{1}$ Acid mucopolysaccharide reference standards, April 1977, M. B. Matthews, J. A. Ciffonelli, Department of Pediatrics, University of Chicago, Chicago, Ill.
} 
Rosenberg (11). Analyses of thrombin concentrations were performed by the modified National Institutes of Health (NIH) procedure (12) described by Mann et al. (13).

Coagulation tests were performed by published methods (14). The appearance of the anticoagulant material throughout the different steps of the isolation and purification procedures were monitored by the thrombin time using crude bovine thrombin reconstituted to yield a normal thrombin time of $16-18 \mathrm{~s}$ in the absence of added inhibitor. As a substrate, $50 \mu \mathrm{l}$ of a $0.15 \mathrm{M} \mathrm{NaCl}$ solution in which the unknown material was dissolved was added to $150 \mu$ l of normal pool of fresh plasma collected in oxalate; as a control, $50 \mu \mathrm{l}$ of $0.15 \mathrm{M} \mathrm{NaCl}$ was added to $150 \mu \mathrm{l}$ of normal plasma. The anticoagulant activity of the material was measured against a standard curve prepared with increasing dilutions of beef lung heparin with $0.15 \mathrm{M} \mathrm{NaCl}$ as a diluent. Because of the variation of the thrombin solution from day to day, such a standard curve was freshly plotted every time an assay of the anticoagulant activity was to be done.

Proteolytic digestion was accomplished by incubating the thawed patient plasma, freshly collected in acid citrate dextrose and stored at $-70^{\circ} \mathrm{C}$, or the isolated proteoglycan from platelet Factor $4(\mathrm{PF} 4)^{2}-$ Sepharose column, with pronase $(3 \mathrm{mg} / 100 \mathrm{ml})$ for $48 \mathrm{~h}$ at $45^{\circ} \mathrm{C}$. At the end of this period, solid trichloroacetic acid was added to $5 \%$ (wt/vol) and incubation continued for $2 \mathrm{~h}$ at $4^{\circ} \mathrm{C}$. The supernate from this as well as two washes of the precipitate with deionized water were exhaustively dialyzed against the water and lyophilized.

PF4 was coupled to aminohexyl Sepharose 4B in the following manner: to $1 \mathrm{ml}$ of packed resin was added $2.5 \mathrm{ml}$ human PF4 $(2.6 \mathrm{mg} / \mathrm{ml})$ in $0.5 \mathrm{M} \mathrm{NaCl}, \mathrm{pH} 5.5,22^{\circ} \mathrm{C}$. $20 \mathrm{mg}$ of solid water-soluble carbodiimide was then added with stirring and the $\mathrm{pH}$ maintained at $4.5-5.5$ by the addition of dilute $\mathrm{HCl}$ over a period of $1 \mathrm{~h}$. Stirring was then continued overnight at $22^{\circ} \mathrm{C}$. The resin was then filtered, washed with $100 \mathrm{ml}$ of $0.02 \mathrm{M}$ Tris- $\mathrm{HCl}, 1.5 \mathrm{M}$ sodium chloride, $\mathrm{pH}$ 7.4. Resin was then washed in $0.02 \mathrm{M}$ Tris- $\mathrm{HCl}, 0.15 \mathrm{M} \mathrm{NaCl}, \mathrm{pH} 7.4$ for storage or further use.

Molecular weight estimations were performed with the high speed sedimentation equilibrium technique (15) using a Beckman model E analytical centrifuge (Beckman Instruments, Inc., Fullerton, Calif.). No gross curvature was observed in high speed sedimentation equilibrium experiments. Therefore, weight average molecular weights ( $\bar{M} w)$ were calculated from direct analysis of the slope of plots of log fringe displacement (lnc) vs. radial distance squared $\left(r^{2}\right)$ using the equation:

$$
\overline{\mathrm{M}} \mathrm{w}=\frac{2 \mathrm{RT}}{\omega^{2}(1-\overline{\mathrm{v}} \rho)} \frac{\mathrm{d} \operatorname{lnc}}{\mathrm{dr}^{2}}
$$

The $\mathrm{Z}$ average molecular weights were calculated by extrapolation of $\bar{M}_{r}$, the weight average molecular weight at any point $r$ to the cell bottom. A value of $0.53 \mathrm{~cm}^{3} / \mathrm{g}(16)$ was used for $\bar{v}$ for the peptidoglycan, since this value (determined for chondroitin 4-sulfate) is appropriate for the degree of sulfation reported for heparan sulfate. A value of $0.61 \mathrm{~cm}^{3} / \mathrm{g}$ was used for the proteoglycan based upon composition (38-41\% protein) and a value of $0.73 \mathrm{~cm}^{3} / \mathrm{g}$ was used for protein.

Speeds were chosen such that $\mathrm{dlnc} / \mathrm{dr}^{2}$ was between 1.5 and 2.5. For all experiments, meniscus depletion and the attainment of equilibrium were verified experimentally.

Amino acid analyses were performed by single column techniques on a Beckman model 119 amino acid analyzer. Before analysis samples were hydrolyzed in $6 \mathrm{~N} \mathrm{HCl}$ for $24 \mathrm{~h}$ at $110^{\circ} \mathrm{C}$. Uronic acid content was measured by the carbazole reaction according to Bitter and Muir (17). Gel electrophoretic analyses

\footnotetext{
${ }^{2}$ Abbreviation used in this paper: PF4, platelet Factor 4.
}

of acid mucopolysaccharide were performed according to the procedure of Horner (18) in lithium acetate buffer and 0.6 or $1.2 \%$ agarose gels. Staining was accomplished using toluidine blue 0 .

Antithrombin III cofactor activity of the isolated anticoagulant was evaluated with purified components. Solutions of the isolated inhibitor at concentrations equivalent to $0.66 \mathrm{U}$ heparin/ $\mathrm{ml}$ (determined from thrombin-time assays on normal

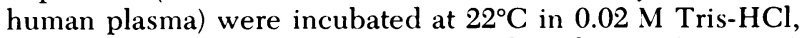
$0.15 \mathrm{M} \mathrm{NaCl}, \mathrm{pH} 7.4$ with bovine antithrombin III $(2.44 \mu \mathrm{M})$ and human $\alpha$-thrombin $(0.856 \mu \mathrm{M})$. At regular intervals after the addition of thrombin aliquots of the reaction mixture were withdrawn and assayed for residual thrombin-catalyzed clotting activity according to the NIH procedure (12) as modified by Mann et al. (13). Control experiments were also performed using an equivalent amount of commercial heparin in place of the isolated anticoagulant. In some instances human PF4 at a final concentration of $0.14 \mathrm{mg} / \mathrm{ml}$ was included to compare the neutralization of the heparin-like cofactor activity of the patient-derived inhibitor to the neutralization of commercial heparin.

The patient's leukocytes, obtained by leukophoresis, were pelleted by centrifugation at $800 \mathrm{~g}$ for $8 \mathrm{~min}$. Cells were then prepared for either short-term culture or homogenization. For short-term cultures, the cells were resuspended in RPMI 1640 medium and cultured in Marbrook vessels (19) as described by Katzmann (20). Cell pellets were homogenized in a pestle tissue grinder maintained at $0^{\circ} \mathrm{C}$. Nuclei and cellular debris were removed by centrifugation at $1,000 \mathrm{~g}$ for $10 \mathrm{~min}$. The supernate of the short-term leukocyte culture did not possess anticoagulant activity, nor did the extracts of homogenized cells.

Case report. The patient was a 68 -yr-old female with a 10-mo history of multiple myeloma (immunoglobulin[Ig]A kappa) who had been treated with L-phenylalanine mustard and prednisone. She presented with generalized petechiae and large hematomata on the upper extremities.

Laboratory studies: hemoglobin $10.2 \mathrm{~g} / 100 \mathrm{ml}$, leukocytes $29,500 / \mathrm{mm}^{3}$ with $63 \%$ plasma cells; platelet count $12,000 /$ $\mathrm{mm}^{3}$; calcium $15 \mathrm{mg} / 100 \mathrm{ml}$, uric acid $6.6 \mathrm{mg} / 100 \mathrm{ml}$, and creatinine $7.2 \mathrm{mg} / 100 \mathrm{ml}$. Total serum protein $7.2 \mathrm{~g} / 100 \mathrm{ml}$ with $4.5 \mathrm{~g} / 100 \mathrm{ml}$ albumin and $0.28 \mathrm{~g} / 100 \mathrm{ml}$ alpha $1,0.92 \mathrm{~g} /$ $100 \mathrm{ml}$ alpha $2,1.4 \mathrm{~g} / 100 \mathrm{ml}$ beta, and $0.82 \mathrm{~g} / 100 \mathrm{ml}$ gamma globulin. The IgA was $4.9 \mathrm{mg} / \mathrm{ml}$, IgM $0.15 \mathrm{mg} / \mathrm{ml}$, and IgG $4.0 \mathrm{mg} / \mathrm{ml}$. The urine was positive for Bence Jones protein and showed a monoclonal kappa spike on immunoelectrophoresis. Bone marrow aspiration showed over $90 \%$ abnormal plasma cells. No mast cells were seen. Coagulation studies are presented in Table I.

\section{RESULTS}

The chromatographic separation of the anticoagulant material present in the patient's plasma on PF4Sepharose is presented in Fig. 1A, whereas the chromatographic behavior of beef lung heparinized-human acid citrate dextrose plasma used as a control is presented in Fig. 1B. In each case, $5 \mathrm{ml}$ of the anticoagulated plasma was allowed to percolate through $\sim 3 \mathrm{ml}$ of PF4Sepharose. The material not bound in each case represents most of the plasma protein present in the original samples. The plasma used in the heparin control was anticoagulated by the addition of $250 \mathrm{U}$ of beef lung heparin, and before application to the column had a clot time of $>100 \mathrm{~s}$. The initial fractions from this column 
TABLE I

Patient's Coagulation Studies*

\begin{tabular}{ll}
\hline $\begin{array}{l}\text { Prothrombin time } \\
\text { Partial thromboplastin time }\end{array}$ & $12(1 \mathrm{l}) \mathrm{s}$ \\
$\begin{array}{l}\text { Activated partial thromboplastin } \\
\quad \text { time }\end{array}$ & $58(45-60) \mathrm{s}$ \\
$\begin{array}{l}\text { Stypven time } \\
\text { Reptilase time }\end{array}$ & $14(15) \mathrm{s}$ \\
$\begin{array}{l}\text { Thrombin time } \\
\text { Thrombin time with equal } \\
\quad \text { volume of normal plasma }\end{array}$ & $600(16-18) \mathrm{s}$ \\
$\begin{array}{l}\text { Thrombin time with } 10 \mu \mathrm{g} / \mathrm{ml} \text { of } \\
\quad \text { protamine sulfate }\end{array}$ & $600 \mathrm{~s}$ \\
$\begin{array}{l}\text { Thrombin time after barium } \\
\quad \text { sulfate adsorption }\end{array}$ & $22 \mathrm{~s}$ \\
$\begin{array}{l}\text { Thrombin time with } 50 \mu \mathrm{g} / \mathrm{ml} \text { of } \\
\quad \text { purified PF4 }\end{array}$ & $24 \mathrm{~s}$ \\
$\begin{array}{l}\text { Antithrombin III } \\
\text { Fibrinogen }\end{array}$ & $19 \mathrm{~s}$ \\
$\begin{array}{l}\text { Fibrin split products } \\
\text { Protamine gel }\end{array}$ & $21(18-24) \mu \mathrm{g} / \mathrm{ml}$ \\
\hline
\end{tabular}

* Normal values in parentheses.

had a thrombin clot time of $22.6 \mathrm{~s}$. Similarly, patient plasma, which before application to the column had a plasma thrombin clot time of $>100 \mathrm{~s}$, exhibited a thrombin clot time for the initial fractions of $25.5 \mathrm{~s}$. Thus, in both the experimental and control PF4-Sepharose column, the anticoagulant activity was removed on the column, and the clottability of the plasma coming through the column was restored. Subsequent elution of the column after washing with $0.5 \mathrm{M}$ sodium chloride, was accomplished with $0.75 \mathrm{M}$ salt. The anticoagulant activity eluted from each column is expressed in terms of the fraction of the quantity of anticoagulant applied to the column based upon the heparin assay described in Methods. Under this set of conditions, anticoagulant activity, some protein (as exhibited by absorbance at $280 \mathrm{~nm}$ ), and uronic acid were elaborated from both the chromatography of the patient plasma and chromatography of the heparinized normal plasma. Subsequent elution of both columns with $1.5 \mathrm{M}$ sodium chloride resulted in the elution of a small amount of additional anticoagulant activity from the patient's plasma and the larger fraction of anticoagulant activity from the column to which the heparinized normal plasma was applied. The appearance of two peaks from each column is a reproducible occurrence that does not appear to be related to individual heparin components in each sample, but rather to anomalous column behavior, in that reapplication of either of the components eluted at $0.75 \mathrm{M}$ or $1.5 \mathrm{M}$ results in a similar chromatographic pattern; that is, two peaks on elution. Most likely this anomalous behavior is a reflection of heterogenous binding of PF4 to the agarose support rather than heterogeneity in the anticoagulant activity applied to the column.
The amount of anticoagulant material present in the patient's plasma was about $30 \mu \mathrm{g} / \mathrm{ml}$, based upon recoveries from the PF4-Sepharose column.

For the column to which the patient's plasma was applied, the components eluted at $0.75 \mathrm{M}$ salt contained, in addition to anticoagulant activity and uronic acid, some proteinaceous components. In addition, immunodiffusion experiments revealed the presence of trace amounts of human antithrombin III in the components eluted in this fraction, whereas sodium dodecyl sulfate gel electrophoretic analysis showed faint amounts of a variety of proteins associated with this peak. The components eluted in the $0.75 \mathrm{M}$ fraction from the patient's plasma were pooled and subjected to chromatography on Bio-Rad P-150. Anticoagulant activity was eluted in the void volume of this column. The material retained its absorbance at $280 \mathrm{~nm}$, suggesting the continued presence of protein.

To compare the patient-derived anticoagulant with commercial heparin, the $0.75 \mathrm{M}$ fraction was subjected to pronase digestion and trichloroacetic acid precipitation to remove the protein component(s). These steps were taken because commercial heparin is obtained only after rigorous proteolytic and chemical digestion of the animal tissue from which the polysaccharide is derived. After this treatment all absorbance at $280 \mathrm{~nm}$ was lost from the anticoagulant preparation, whereas the anticoagulant activity was completely recovered. A comparison of the gel filtration behavior of this material with commercial heparin, using $10 \%$ agarose, is presented in Fig. 2. In contrast with commercial heparin, the patient-derived anticoagulant peptidoglycan is excluded from a $10 \%$ agarose column and appears to be of substantially larger size than commercial beef lung heparin.

The isolated peptidoglycan was subjected to agarose gel electrophoretic analysis in lithium acetate, $\mathrm{pH} 3$, to compare its relative electrophoretic mobility to that of other known sulfated polysaccharide standards. The electrophoretic mobility of the acid mucopolysaccharides are functions of their charge density, and most of these can be distinguished electrophoretically. Represented in Fig. 3 is a photograph of agarose gel electrophoretograms of reference standard acid mucopolysaccharides and the anticoagulant peptidoglycan derived from the patient's plasma. Reference standard acid mucopolysaccharides are present in gels B through $\mathrm{H}$. The dyefront marker, amaranth, is in gel $\mathrm{K}$. The patient-derived anticoagulant is present in gels $\mathrm{A}, \mathrm{I}$, and $\mathrm{J}$; as the isolated material (gel A), as the isolated material mixed with heparin (gel I), and the isolated material mixed with heparan sulfate (gel J). It can be seen that the patient-derived peptidoglycan anticoagulant is electrophoretically homogeneous in this system and is entirely distinguished from heparin and five of the other sulfated polysaccharide reference standards used for comparison. 

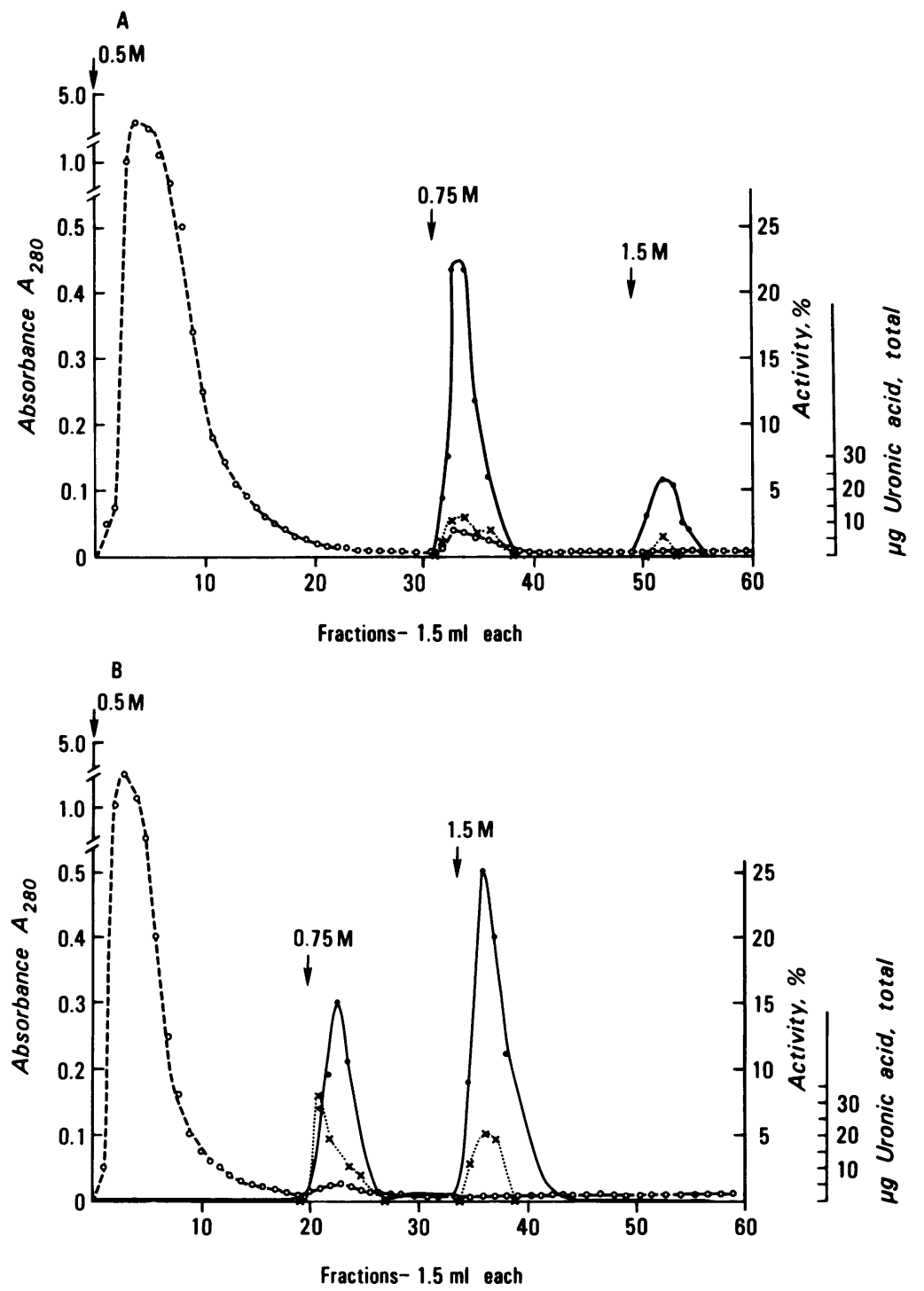

FigURE 1 (A) Chromatography of patient ACD plasma on human PF4-aminohexyl Sepharose and (B) of heparin anticoagulated normal human acid citrate dextrose plasma on human PF4aminohexyl Sepharose. Absorbance at $280 \mathrm{~nm}(O)$, anticoagulation activity $(\odot)$, and uronic acid content $(x)$ are plotted vs. fraction member.

The material undergoes coelectrophoresis with heparan sulfate. Subsequent to this experiment, reference standard heparan sulfate was subjected to PF4-Sepharose affinity chromatography, and was shown to behave in similar fashion to the anticoagulant derived from the patient's plasma.

The amino acid composition of the proteoglycan relative to uronic acid composition is presented in Table Il. The sum for amino acid composition indicates about 2.23 amino acids per hexuronic acid residue. For heparan sulfate, the hexuronic acid content corresponds to $44(21)-49 \%^{1}$ of the total polysaccharide unit mass. If one presumes that the material isolated from the pa- tient is a proteoglycan for which the acid polysaccharide portion is heparan sulfate, one can estimate a weightfraction protein of from 38 to $41 \%$ based upon the amino acid to hexuronic acid ratio. After pronase treatment, $85 \%$ of the amino acids are lost from the total composite to provide a ratio of 0.317 amino acids per uronic acid residue for the peptidoglycan. Again assuming that the acid polysaccharide is heparan sulfate for which the polysaccharide chain is $44-49 \%$ hexuronic acid, the peptidoglycan resulting from pronase digestion corresponds to $\sim 91-92 \%$ acid polysaccharide with $8-9 \%$ of residual (not digestible by pronase) peptide material.

Frequently, gel filtration has been used to estimate 


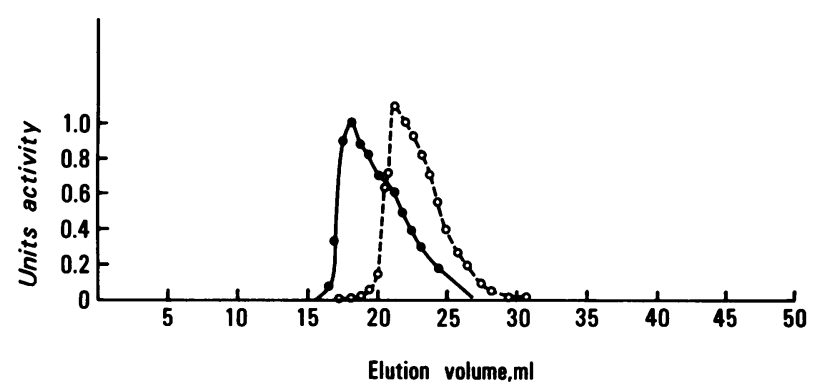

FIGURE 2 Elution profiles of pronase-digested, TCA-treated anticoagulant (O) and Upjohn heparin (O) on a gel filtration column prepared with $10 \%$ agarose. Relative anticoagulant activity is plotted vs. elution volume. The void volume for the column is $\sim 18 \mathrm{ml}$.

the physical size of acid mucopolysaccharides. Gel filtration chromatography as a technique for molecular weight estimation, is somewhat complicated by the need to calibrate the gel filtration column in question with an appropriate set of markers that represent model compounds of known chemical structure and molecular weight, which are the hydrodynamic equivalents of the molecule whose molecular size is to be estimated. When used for the analysis of complex proteoglycans that may have peptide backbone as well as multichain or branch chain structures, gel filtration analysis can lead to gross error. For these reasons and the fact that we do not have detailed knowledge of the nature of the structure of the anticoagulant, we chose to evaluate the mass

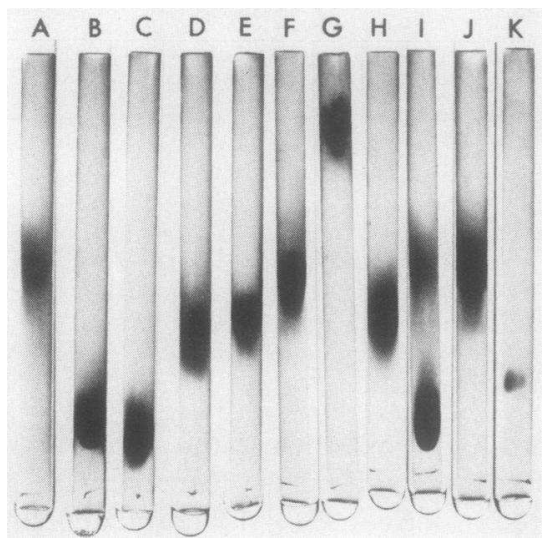

Figure 3 Lithium acetate-agarose electrophoretic analysis of reference standard acid mucopolysaccharides and patientderived peptidoglycan. Gel A contains patient-derived peptidoglycan anticoagulant; gel $\mathrm{B}$, reference standard heparin; gel C, heparin obtained from Upjohn; gel D, keratan sulfate; gel $\mathrm{E}$, dermatan sulfate; gel $\mathrm{F}$, heparan sulfate; gel $\mathrm{G}$, hyaluronic acid; gel $\mathrm{H}$, chondroitin-6-sulfate; gel $\mathrm{I}$, patient anticoagulant peptidoglycan mixed with reference standard heparin; gel J, patient peptidoglycan anticoagulant mixed with reference standard heparan sulfate; and gel $\mathrm{K}$, amaranth dye marker.
TABLE II

Amino Acid Composition of Anticoagulant Material

\begin{tabular}{lcc}
\hline & Protenglycan & Peptidoglycan \\
\hline & \multicolumn{2}{c}{ mol/mol uronic acid } \\
Aspartic acid & 0.18 & 0.035 \\
Threonine & 0.14 & 0.032 \\
Serine & 0.26 & 0.030 \\
Glutamic acid & 0.32 & 0.049 \\
Proline & 0.16 & 0.031 \\
Glycine & 0.32 & 0.037 \\
Alanine & 0.18 & 0.023 \\
Valine & 0.11 & - \\
Methionine & 0.02 & - \\
Isoleucine & 0.05 & - \\
Leucine & 0.12 & 0.009 \\
Tyrosine & 0.05 & - \\
Phenylalanine & 0.08 & 0.014 \\
Histidine & 0.08 & 0.009 \\
Lysine & 0.09 & 0.009 \\
Arginine & 0.07 & 0.009 \\
Hexuronic acid & 1.0 & 1.0 \\
Amino acid & 2.23 & 0.317 \\
& &
\end{tabular}

of the patient-derived anticoagulant by analytical ultracentrifugation. A most precise analysis of sedimentation equilibrium data requires knowledge of the total composition of the material for the calculation of the partial specific volume terms. At present, detailed total compositions for the patient-derived anticoagulant is not available. However, sufficient partial composition data is available to permit estimation of the appropriate partial specific volume term for the peptidoglycan and proteoglycan (see Methods).

We have performed sedimentation equilibrium experiments with the isolated patient anticoagulant under three sets of conditions. The data are summarized in Table III. Two sets of experiments were performed with the intact, protease nondigested anticoagulant. In dilute aqueous buffers, the molecular weight of the anticoagulant and any noncovalently associated materials are measured. Under this set of conditions, an average molecular weight of 111,000 was obtained, presuming a partial specific volume of $0.61 \mathrm{~cm}^{3} / \mathrm{g}$. The sedimentation equilibrium data obtained under these sets of conditions showed some evidence of nonideal behavior near the cell bottom. However, this problem was not sufficiently severe so as to preclude an accurate interpretation of the data. Sedimentation equilibrium experiments were also performed with the isolated proteoglycan in the presence of $6 \mathrm{M}$ guanidinium chloride. Under this set of conditions, noncovalent interactions between the covalent proteoglycan unit and any other noncovalent associated entities would be destroyed and the molecular weight obtained should reflect the mass of the covalent anticoagulant unit. 
TABLE III

Molecular Weight of Anticoagulant

\begin{tabular}{|c|c|c|c|c|}
\hline Preparation & Solvent & $\bar{v}$ & Molecular weight & Amino acid \\
\hline & & $\mathrm{cm}^{3 / g}$ & & $\%$ \\
\hline PF4 chromatography & $0.15 \mathrm{M} \mathrm{NaCl}$ & 0.61 & 111,000 & $38-41$ \\
\hline P-150 chromatography & $\begin{array}{c}0.02 \mathrm{M} \text { Tris } \\
\mathrm{pH} 7.4\end{array}$ & & & \\
\hline $\begin{array}{l}\text { PF4 chromatography } \\
\text { P-150 chromatography }\end{array}$ & $\begin{array}{l}6 \text { M Guanidinium } \\
\text { Chloride }\end{array}$ & 0.61 & 116,000 & $38-41$ \\
\hline PF4 chromatography & $0.15 \mathrm{M} \mathrm{NaCl}$ & 0.53 & 42,000 & $8-9$ \\
\hline P-150 chromatography & $0.02 \mathrm{M}$ Tris & & & \\
\hline Pronase digestion & $\mathrm{pH} 7.4$ & & & \\
\hline TCA precipitation & & & & \\
\hline
\end{tabular}

Under these sets of conditions, an average mol wt of 116,000 was obtained, again presuming that the partial specific volume of the proteoglycan is $0.61 \mathrm{~cm}^{3} / \mathrm{g}$. Pronase digestion of the proteoglycan anticoagulant removed $\sim 86 \%$ of the amino acid material initially associated with the anticoagulant and the resulting polymer gave a mol wt of 42,000 when examined in the analytical ultracentrifuge, presuming a partial specific volume of $0.53 \mathrm{~cm}^{3} / \mathrm{g}$. The relative homogeneity of the polysaccharide unit is illustrated in the sedimentation equilibrium data presented in Fig. 4. These data clearly show that the polysaccharide is not highly polydisperse. In addition the $\overline{\mathbf{M}} \mathrm{z}$ value determined for this analysis was 48,000 , indicating a relatively narrow range of molecular weights for the polysaccharide mass distribution. Approximately 9\% of this material is amino acid by composition data, and thus the polysaccharide mol wt is 38,000 .

A composite of analysis of the molecular weight and composition data obtained for the proteoglycan isolated

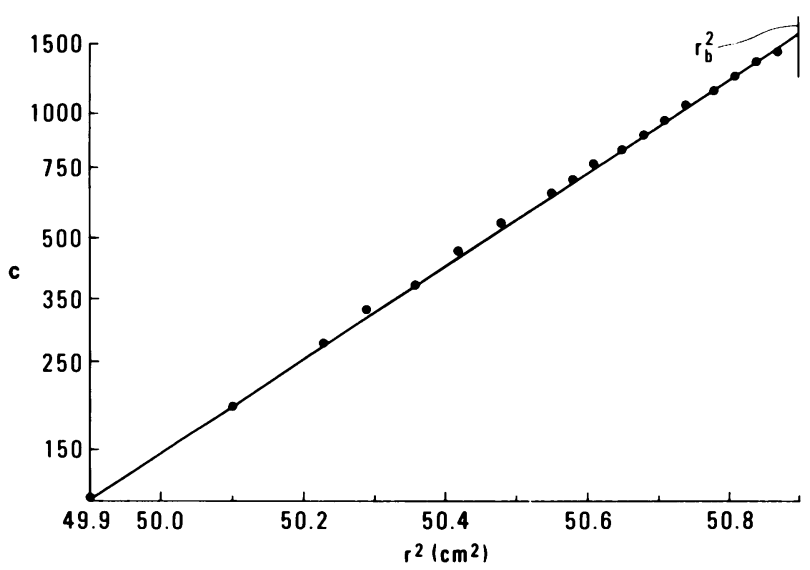

Figure 4 Sedimentation equilibrium distribution for peptidoglycan, at $18,000 \mathrm{rpm}\left(22.3^{\circ} \mathrm{C}\right)$. Concentration (c) is plotted vs. radial distance squared. The cell bottom is signified by $r_{b}^{2}$. from the patient's plasma would suggest the structure containing two polysaccharide chains of $38,000 \mathrm{~mol} \mathrm{wt}$ linked to a peptide chain (or chains) whose total mass would be $\sim 39,000$. Such a structure would be $\sim 66 \%$ carbohydrate and $34 \%$ peptide. These values are within $4-7 \%$ of the estimated composition values based upon the partial composition data available. The consistency between the values obtained from the proteoglycan in the native state in dilute aqueous buffer $(111,000)$ and that obtained in $6 \mathrm{M}$ guanidinium chloride $(116,000)$, and the consistency between the values obtained for relative fraction of peptide to carbohydrate based upon both chemical analysis and physical analysis strongly suggest that the appropriate assumptions have been made with respect to partial specific volume for the intact proteoglycan based upon the partially assumptive analysis of composition of the patient-derived anticoagulant.

Functional assays of the relative anticoagulant potency of the patient-derived peptidoglycan were conducted by comparing its effects to that of commercial heparin on a plasma-thrombin clot time. The patient-derived anticoagulant had a specific activity of $\sim 8 \mathrm{U} / \mathrm{mg}$, which is substantially less than the specific activity of the commercial beef lung heparin, which has a specific activity of $\sim 120 \mathrm{U} / \mathrm{mg}$.

The nature of the interaction of the patient-derived anticoagulant peptidoglycan with antithrombin III, thrombin, and PF4 were compared to that of beef lung heparin. The results of these experiments are presented in Fig. 5. The thrombin inhibition data for each of the experiments presented in Fig. 5 are expressed as pseudo first-order reactions. The amount of patient-derived anticoagulant or beef lung heparin added to antithrombin III (closed and open circles, respectively), are equivalent based upon the plasma thrombin clot time assay described in Methods. Upon administration of PF4 to the mixture of heparin, antithrombin III, and thrombin or that containing patient-derived prote- 


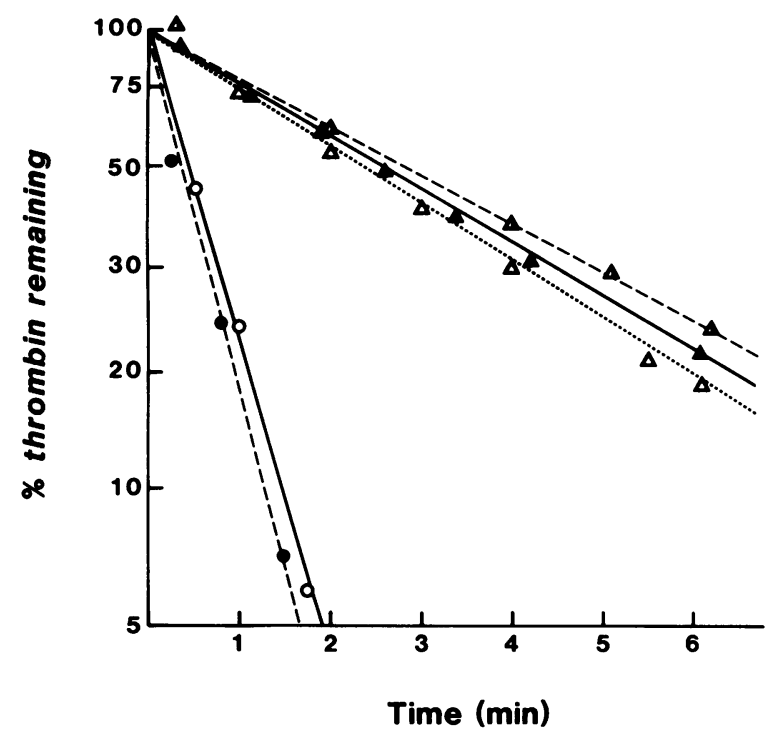

FIgURE 5 Thrombin inhibition by antithrombin III in the presence of commercial beef lung heparin or patient-derived anticoagulant. The reaction is analyzed as a pseudo first-order reaction in terms of the logarithm of the percent thrombin remaining as a function of time (minutes). The time-dependent decrease of thrombin activity with antithrombin III alone is shown $(\triangle)$. The mixture of antithroimbin III, thrombin, and patient-derived anticoagulant ( 0.66 heparin equivalent $\mathrm{U} / \mathrm{ml}$ ) is shown (O) and a mixture of antithrombin III, thrombin, and heparin $(0.66$ units $/ \mathrm{ml})$ is given $(O)$. Results obtained by adding PF $4(0.14 \mathrm{mg} / \mathrm{ml})$ to these two samples are designated by $\Delta$ and $\Delta$, respectively.

oglycan anticoagulant, antithrombin III, and thrombin, equivalent rates of inactivation for thrombin were observed. These rates obtained after neutralization of heparin and heparin-like anticoagulant are experimentally equivalent to the rate of neutralization of the equivalent amount of thrombin by the equivalent amount of antithrombin III alone (Fig. 5, open triangles). It should be noted here that the rate observed and presented for Fig. 5 inhibition of thrombin in the presence of heparin is not the ultimate rate that could be observed upon saturation of the reaction with heparin. The concentration of heparin used in this experiment was chosen such that the rate of decrease of thrombin activity could be measured. If saturating amounts of patient proteoglycan or commercial heparin are added to the amount of antithrombin III present in the reaction mixture, the experimental data would show inhibition of all thrombin present at the earliest time of analysis. Under conditions of the saturation of the antithrombin III present either by patient-derived proteoglycan or by heparin, complete return to the antithrombin III alone inhibition rate is observed upon administration of PF4. The rate constants derived from these experiments are presented in Table IV.
TABLE IV

Rate of Thrombin Inhibition

\begin{tabular}{ccc}
\hline Component added & $\mathrm{k}^{*}$ & Half-life \\
\hline & $\begin{array}{l}\text { liter } \cdot \min ^{-1} . \\
\operatorname{mol}^{-1} \times 10^{-5}\end{array}$ & $\min$
\end{tabular}

Antithrombin III + PF4

1.22

6.51

2.33

Antithrombin III + heparin

6.91

0.44

Antithrombin III + anticoagulant\$

Antithrombin III + heparin + PF4

1.03

0.41

Antithrombin III + anticoagulant

+ PF4

1.10

2.57

* The second-order rate constant $\left(\right.$ at $\left.22^{\circ} \mathrm{C}\right)$ determined from pseudo first-order plots with AT-III in 2.85-fold mol excess over IIa.

\$ Heparin (intestinal mucosa) obtained from Eli Lilly \& Co., Indianapolis, Ind.

$\S$ Patient-derived proteoglycan anticoagulant.

\section{DISCUSSION}

The anticoagulant activity present in this patient's plasma could be quantitatively bound to and subsequently eluted from PF4 immobilized on agarose. The chemical and physical data derived from studies of the anticoagulant suggest that it is likely composed of two polysaccharide chains of nearly identical size interconnected by peptide material. Whereas current data indicates that the polysaccharide chains present in the anticoagulant proteoglycan are of nearly identical size, no knowledge is presently available as to whether a single or multiple polypeptides are responsible for the protein constituent of the proteoglycan. In any event, the protein constituents do not appear to have an influence on the anticoagulant activity of the proteoglycan, in that pronase digestion leaves this activity intact with the peptidoglycan. Further, the anticoagulant activity associated with the peptidoglycan is consistent with its behavior as an antithrombin III cofactor in a manner completely analogous to heparin. Electrophoretic analysis of the peptidoglycan anticoagulant indicates that the isolated material behaves more like heparan sulfate than heparin.

The molecular weight of commercially available heparin is reported to be in the range of $6,000-16,000$ (21-23). The molecular weight of the reference standard heparan sulfate used for electrophoretic and chromatographic comparisons can be estimated to be in the range of 30,000-40,000 based upon intrinsic viscosity data ${ }^{1}$ supplied with the material. Both of these materials were isolated with harsh chemical extraction procedures and proteolytic digestion of the animal tissue. In contrast, macromolecular heparin has been observed on more gentle extraction of cultures of mast cells $(24,25)$, and from rat skin $(26,27)$. In these cases, the major 
heparin fraction obtained was resistent to protease digestion but could be reduced in size by alkaline hydrolysis, oxidative-reductive depolymerization with ascorbic acid, or by cleavage by heparinases. The products obtained by the chemical treatments had mol wt near 40,000, whereas the enzymatic digestion products had a mol wt of about 14,500.

Heparan sulfates are found in a variety of tissues including the aorta $(28,29)$, and apparently are susceptible to change with both age (30) and disease (31), including cellular transformation (32-34). In contrast to heparin, which appears to be a complex macromolecular polysaccharide structure with additional protein attached, heparan sulfate appears to be a proteoglycan with a peptide backbone to which a series of polysaccharide chains is connected. Jansson and Lindahl (35) reported the isolation of a heparan sulfate proteoglycan from aorta that had an apparent mol wt of 70,000 and could be cleaved to produce polysaccharide chains with a mol wt of 10,000. Chiarugi and Urbano (36) reported the isolation of a heparan sulfate proteoglycan for normal and Rous sarcoma virus transformed baby hampster kidney cells which was $\sim 40 \%$ protein and had a mol wt of 130,000 , somewhat similar to the value obtained for our material.

Circulating anticoagulants have been known to occur in a broad variety of conditions. Some of these anticoagulants, such as the lupus anticoagulant, cause an immediate inhibition of the coagulation mechanism whereas others are directed against specific coagulation factors, particularly factor VIII (37). In multiple myeloma, however, specific abnormalities in the clotting mechanisms have not frequently been characterized. Prolongation of prothrombin and partial thromboplastin times have generally been attributed to nonspecific interference of the monoclonal proteins, although in certain instances specific coagulation factor antibodies have been elaborated in myeloma ( 1 ). In several studies $(4,5,38)$, an antithrombin role has been assigned to a protein in the plasma which may, or may not, have been the monoclonal immunoglobulin molecule. In two studies $(39,40)$ heparin-like activity for an anticoagulant was suggested but further analyses were not conducted to specifically identify the nature of the anticoagulant activity. In the patient whose anticoagulant is the subject of this investigation, the anticoagulant material appears to have no specific relationship to the immunoglobulin elaborated by the myeloma cell line, and, in fact, the patient's disease was in remission and IgA at a normal level when the spontaneously occurring anticoagulant activity developed. The observation of a circulating heparan sulfate proteoglycan in this patient is provocative in view of reports suggesting differences with respect to heparan sulfate in mucopolysaccharide components after cell transformation (32-34). Although this particular patient had a plasma cell leukemia, the anticoagulant activity was not elaborated in short-term cultures of her peripheral leukocytes, nor was it present in the extracts of homogenates of the cultured cells. Thus, although this anticoagulant molecule was generated in the blood of the individual suffering from plasma cell leukemia, no direct connections between the disease state and the anticoagulant molecule can be identified.

Two potential routes by which the anticoagulant molecule may have appeared in the plasma appear worthy of some speculation. These are: (a) that the anticoagulant molecule is a normal constituent of plasma, ordinarily present only at very low concentrations, which was released at a greater rate as a consequence of the disease state; and (b) that tissue damage secondary to the primary disease state has led to the release of the proteoglycan. Heparan sulfate and related substances have been reported to be produced by endothelial cells in culture (6); in addition, Muller et al. (41) have reported a heparin-like inhibitor in the blood of the newborn, and it is conceivable that the anticoagulant described in the present work is related to these materials.

\section{ACKNOWLEDGMENTS}

We would like to thank Dr. Jerry A. Katzmann for performing the short-term cell culture experiments described in this paper. We would also like to thank Dr. Matthews and Dr. Ciffonelli for providing the mucopolysaccharide reference standards used for comparison. Finally, we would like to acknowledge Dr. Robert Kyle and Dr. Philip Greipp for making the plasma of this patient available for our studies.

This research by grant HL-07049 from the National Heart, Lung, and Blood Institute.

\section{REFERENCES}

1. Perkins, H. A., M. R. MacKenzie, and H. Fudenberg. 1970. Hemostatic defects in dysproteinemias. Blood. 35: 5, 695-707.

2. Glueck, H. E., and R. Hong. 1965. A circulating anticoagulant in $\gamma 1-\mathrm{A}$ multiple myeloma: Its modification by penicillin. J. Clin. Invest. 44: 1866-1881.

3. Vigliano, E. M., and H. Horowitz. 1967. Bleeding syndrome in a patient with IgA myeloma: interaction of protein and connective tissue. Blood. 29: 6, 823-836.

4. Cohen, I., J. Amir, Y. Ben-Shaul, A. Pick, and A. De Vries. 1970. Plasma cell myeloma associated with an unusual myeloma protein causing impairment of fibrin aggregation and platelet function in a patient with multiple malignancy. Am. J. Med. 48: 766-776.

5. Lackner, H., V. Hunt, M. B. Zucker, and J. Pearson. 1970. Abnormal fibrin ultrastructure, polymerization and clot retraction in multiple myeloma. Br. J. Hematol. 18: 625636.

6. Buonassisi, V., and M. Root. 1975. Enzymatic degradation of heparin-related mucopolysaccharides from the surface of endothelial cell culture. Biochim. Biophys. Acta. 385: $1-10$.

7. Kraemer, P. M. 1971. Heparan-sulfates of cultured cells to acid soluble and precipitable species of different cell lines. Biochemistry. 10: 1445-1451.

8. Horner, A. A. 1975. Heparin Structure Function and 
Clinical Implications. R. A. Bradshaw and S. Wessler, editors. Plenum Press, New York. 85-93.

9. Ruiz, C. E., D. N. Fass, V. Fuster, and K. G. Mann. 1976. Isolation and partial characterization of porcine platelet antiheparin factor. Circulation. 54(Suppl. II): 198. (Abstr. 775).

10. Lundblad, R., H. J. Kingdon, and K. G. Mann. 1976. Proteolytic enzymes (Part B). Thrombin. Methods Enzymol. 45: 156.

11. Damus, P. S., and R. D. Rosenberg. 1976. Antithrombinheparin cofactor. Methods Enzymol. 45: 653-669.

12. Minimum Requirements for Dried Thrombin. 1946. National Institutes of Health, Bethesda, Md.

13. Mann, K. G., C. M. Heldebrant, and D. N. Fass. 1971. Multiple active forms of thrombin. 1. Partial resolution differential activities and sequential formations. J. Biol. Chem. 246: 5994-6001.

14. Bowie, E. J. W., J. H. Thompson, Jr., P. Didisheim, and C. A. Owen, Jr. 1971. Laboratory Manual of Hemostasis. W. B. Saunders, Philadelphia. 186.

15. Yphantis, D. A. 1964. Equilibrium ultracentrifugation of dilute solutions. Biochemistry. 3: 297-317.

16. Muir, H., and T. E. Hạrdingham. 1975. Structure of proteoglycans. In MTP International Review of Sciences, Biochemistry Series One. 5: 153-222. University Park Press, Baltimore, Md.

17. Bitter, T., and H. M. Muir. 1962. A modified uronic acid carbazole reaction. Anal. Biochem. 4: 330-334.

18. Horner, A. A. 1967. Electrophoresis of acidic mucopolysaccharides in agarose gel. Can. J. Biochem. 45: 7, $1009-1013$.

19. Marbrook, J. 1967. Primary immune response in cultures of spleen cells. Lancet. II: 1279.

20. Katzmann, J. A. 1978. Myeloma-induced immunosuppression: a multistep mechanism. J. Immunol. 121: 4, 14051409.

21. Roden, L., J. R. Baker, J. A. Cifonelli, and M. B. Matthews, 1972. Isolation and characterization of connective tissue polysaccharides. Methods Enzymol. 28: 73-140.

22. Ciffonelli, J. A. 1975. Relation of chemical structure of heparin to its anticoagulant activity. In Heparin Structure Function and Clinical Implications. R. A. Bradshaw and S. Wessler, editors. Plenum Press, New York. pp 95-103.

23. Lasker, S. E. 1975. Low molecular weight derivatives of heparin that is orally active in mice. In Heparin Structure Function and Clinical Implications. R. A. Bradshaw and S. Wessler, editors. Plenum Press, New York. pp 119- 130.

24. Yurt, R. W., R. W. Leid, Jr., K. F. Austen, and J. E. Silbert. 1977. Native heparin from rat peritoneal mast cells. $J$. Biol. Chem. 252: 518-521.

25. Ogren, S., and U. Lindahl. 1975. Cleavage of macromolecular heparin by an enzyme from mouse mastocytoma. J. Biol. Chem. 250: 2690-2697.
26. Horner, A. A. 1971. Macromolecular heparin from rat skin. Isolation, characterization and depolymerization with ascorbate. J. Biol. Chem. 246: 231-239.

27. Horner, A. A. 1972. Enzymic depolymerization of macromolecular heparin as a factor in control of lipoprotein lipase activity. Proc. Natl. Acad. Sci. U. S. A. 69: 3469-3473.

28. Radhakrishnamurty, B., H. A. Ruiz, Jr., and G. S. Berenson. 1977. Isolation and characterization of proteoglycans from bovine aorta. J. Biol. Chem. 252: 4831-4841.

29. Ogema, T. R., Jr., V. C. Hascall, and R. Eisenstein. 1979. Characterization of bovine aorta proteoglycan extracted with guanidine hydrochloride in the presence of protease inhibitors. J. Biol. Chem. 254: 1312-1318.

30. Kumar, V., G. S. Berenson, H. Ruiz, E. R. Dalferes, Jr., and J. P. Strong. 1967. Acid mucopolysaccharides of human aorta. 1. Variations with maturation.J. Atheroscler. Res. 7: 573-581.

31. Berenson, G. S., S. R. Sriniveasan, P. J. Dolan, and B. Radhakrishnamurty. 1971. Lipoprotein acid mucopolysaccharide complexes from fatty streaks of human aorta. Circulation. 44(Suppl. II): 6. (Abstr. 20)

32. Johnston, L. S., K. L. Keller, and J. M. Keller, 1979. Heparin sulfates of Swiss mouse 3T3 cells. The effect of transformation. Biochim. Biophys. Acta. 583: 81-94.

33. Smith, H. S., A. J. Hiller, E. W. Kingsbury, and C. RobertsDory. 1973. Cell surface properties and the expression of SV40 induced transformation. Nat. New Biol. 245: 6769.

34. Minnikin, S. M., and A. Allen. 1973. Cell surface mucosubstances from trypsin disaggregation of normal and virustransformed lines of baby-hamster kidney cells. Biochem. J. 134: 1123.

35. Jansson, L., and U. Lindahl. 1970. Evidence for the existence of a multichain proteoglycan of heparin sulfate. Biochem. J. 117: 699-702.

36. Chiarugi, V. P., and P. Urbano. 1973. Studies on cell current macromolecules in normal and virus transformed EHK/21C13 cells. Biochim. Biophys. Acta. 298: 195-208.

37. Feinstein, D. I., and S. I. Rappaport. 1970. Progress in Hemostasis and Thrombosis. T. H. Spaet, editor. Gruen \& Stratton, Inc., New York. 75-95.

38. Verstraete, Par M., and C. Vermylen. 1959. Recherches sur L'Antithrombine V dans la Maladie de Kahler. Acta Haematol. 22: 240-254.

39. Vermylen, C., and M. Verstraete. 1961. Antithrombin V: Critical evaluation of its assessment and properties. Thromb. Diath. Haemorrh. 5: 267-284.

40. Harbaugh, M. E., E. M. Hill, and R. B. Conn. 1975. Antithrombin and antithromboplastin activity accompanying IgG myeloma. Am. J. Clin. Pathol. 63: 57-67.

41. Muller, A. D., J. M. Van Doorm, and H. C. Hemker. 1977. Heparin-like inhibitor of blood coagulation in normal newborn. Nature (Lond.). 267: 616-617. 